\title{
Iterative Full-Wave Analysis of Mandelbrot-Inspired Fractal Patch Antenna on Textile Substrate for UWB Applications
}

\author{
V. P. Silva Neto ${ }^{1,2}$ and A. G. D'Assunção ${ }^{2}$ \\ ${ }^{1}$ Federal Rural University of the Semi-Arid Region, DEE, RN 233, Km 01, Zona Rural de Caraúbas, RN, Brazil \\ ${ }^{2}$ Federal University of Rio Grande do Norte, UFRN-CT-DCO, Caixa Postal 1655, 59078-970 Natal, RN, Brazil \\ Correspondence should be addressed to V. P. Silva Neto; valdemir.neto@ufersa.edu.br
}

Received 20 June 2017; Accepted 1 August 2017; Published 7 November 2017

Academic Editor: Jaume Anguera

Copyright (C) 2017 V. P. Silva Neto and A. G. D’Assunção. This is an open access article distributed under the Creative Commons Attribution License, which permits unrestricted use, distribution, and reproduction in any medium, provided the original work is properly cited.

\begin{abstract}
This work presents the analysis of monopole microstrip antennas with truncated ground plane and patch geometry inspired on the Mandelbrot fractal curve for applications in UWB systems. The proposed antenna geometry is analyzed using the Wave Concept Iterative Procedure (WCIP), a full-wave method. Results for the proposed antenna operating frequency, bandwidth, VSWR, gain, and radiation pattern are obtained and discussed. The WCIP results are compared with simulation results provided by HFSS software, for validation purpose. In addition, a prototype antenna is built and measured. A good match between WCIP theoretical and simulation, HFSS simulation, and measurement results is observed for the antenna frequency response.
\end{abstract}

\section{Introduction}

The continuous advance in wireless communication systems has motivated many researchers worldwide to investigate and develop antennas for ultrawideband (UWB) system applications. The great interest in this particular antenna topic is due to several factors such as immunity to the spreading of multipath, difficulty in accessing signal invader users, less interference when compared to narrowband communications, and low cost. Particularly, microstrip antenna structures are an option of great attractiveness to design UWB antennas with excellent performances.

An UWB signal is defined as every signal that occupies a minimum bandwidth of $500 \mathrm{MHz}$ in a particular $7.5 \mathrm{GHz}$ band (from $3.1 \mathrm{GHz}$ to $10.6 \mathrm{GHz}$ ), based on the spectral overlap, since much of this spectrum band is used by existing services and technologies [1-3]. Applications of UWB system are very attractive because, due to the required low-power levels, this system can coexist with other technologies operating in the same frequency band networks, such as IEEE 802.11, GSM, and Bluetooth.

This paper describes the analysis of a monopole microstrip antenna printed on textile substrate for applications in
UWB systems. The use of textile substrate is justified by the increasing need to develop lightweight and flexible devices that could be attached to garments and applied in several areas. For example, several authors have investigated the use of textile substrates, such as microstrip antenna substrates, for applications in biomedical fields [4], surveillance and security systems [5], and telecommunications systems [6].

The patch geometry of the proposed antenna is based on the Mandelbrot escape fractal curve [7, 8]. Results for resonant frequency, bandwidth, radiation pattern, and VSWR are obtained using the Wave Concept Iterative Procedure (WCIP). The WCIP is a full wave formulation that has been widely used in recent years in the analysis and characterization of various microwave circuits [9-15].

Over the years, several authors have studied the application of fractal geometry in the design of planar antennas and printed antennas for UWB applications [16-18]. In [16], a low-profile compact CPW-fed fractal patch antenna based on a slotted circular shape was proposed for UWB applications. A monopole antenna comprising a fractal radiating patch with folded $\mathrm{T}$-shaped element was designed to operate over the entire UWB frequency range [17]. A 
miniaturized UWB monopole antenna designed by the combination of two fractal geometries was proposed in [18]. Giusepe Peano and Sierpinski Carpet fractals were used to design the microstrip patch antenna.

For comparison purpose, simulations are performed using the finite element method, implemented in the commercial software Ansoft HFSS. In addition, a prototype has been fabricated and measured. Good agreement has been observed between the results obtained by WCIP formulation, HFSS simulations, and experiments.

\section{WCIP Formulation}

The WCIP method is a full-wave iterative method whose formulation is based on the electromagnetic wave concept [9-14]. It is a method that has been widely used by many researchers worldwide in the analysis of different types of microwave circuits such as antennas, filters, and frequency selective surfaces (FSS), including printed circuits on textile substrates, as presented in recent studies $[13,14]$.

The WCIP formulation is based on the relationship between incident and reflected waves at the interface of the circuit under investigation [11]. The relationship between the incident $\left(\vec{A}_{i}^{(k)}\right)$ and reflected $\left(\vec{B}_{i}^{(k)}\right)$ waves is described by the method's basic equations:

$$
\begin{aligned}
& \vec{B}_{i}^{(k)}=\widehat{S} \vec{A}_{i}^{(k)}+\vec{A}_{0}^{(1)}, \\
& \vec{A}_{i}^{(k)}=\widehat{\Gamma} \vec{B}_{i}^{(k)},
\end{aligned}
$$

where $k(=1,2)$ corresponds to the circuit interface sides 1 (front) and 2 (back). Also, $i(=1,2,3, \ldots)$ represents the order number of the incident $\left(\vec{A}_{i}^{(k)}\right)$ and reflected $\left(\vec{B}_{i}^{(k)}\right)$ waves at the same circuit interface side $k \cdot \vec{A}_{0}^{(1)}$ represents the initial (first) incident wave.

The relationship taking place between the incident and reflected waves in front of the circuit interface under analysis is described in (1). Thus, $\widehat{S}$ is the "circuit" scattering operator, defined in the space domain and responsible for describing the boundary conditions at the circuit interface [11].

The relationship between the incident and reflected waves in the propagation medium apart from the circuit interface under analysis is described in (2). Thus, $\widehat{\Gamma}$ is the "circuit" reflection operator, defined in the modal domain and responsible for describing the propagation characteristics apart from the circuit interface. The determination of the scattering and reflection operators is presented in [11].

The iterativity of the WCIP method is obtained using the parameters' relationships in (1) and (2), which are determined by the transformation between the space and modal domains used in the WCIP formulation. The transition between spatial and modal domains is obtained by applying the Fourier modal transform, for rectangular symmetry type, defined in the following [15].

$$
\begin{aligned}
{\left[\begin{array}{l}
B_{m n}^{\mathrm{TE}} \\
B_{m n}^{\mathrm{TM}}
\end{array}\right] } & =\operatorname{FMT}\left[\begin{array}{l}
B_{x}(i, j) \\
B_{y}(i, j)
\end{array}\right] \\
& =\frac{\sqrt{2 \delta_{m n} / a b}}{\sqrt{m^{2} / a}+n^{2} / b}\left[\begin{array}{cc}
\frac{n}{b} & -\frac{m}{a} \\
\frac{m}{a} & \frac{n}{b}
\end{array}\right] \operatorname{FFT}\left[\begin{array}{l}
B_{x}(i, j) \\
B_{y}(i, j)
\end{array}\right],
\end{aligned}
$$

where $B_{x}(i, j)$ and $B_{y}(i, j)$ represent the $x$ and $y$ components, respectively, of the wave in the spatial domain and $a$ and $b$ are the circuit dimensions along the $x$ - and $y$-axes, respectively; $\delta_{m n}$ is normalization constant of the orthonormal modal basis for $\mathrm{TE}_{m n}$ and $\mathrm{TM}_{m n}$ modes that propagate in the rectangular waveguide [15].

The Fourier modal transform (FMT) allows you to define the amplitudes of the waves as expansions of TE and TM modes, in the modal domain. This transformation allows the transition of the waves from the spatial domain to the modal domain. The antitransform or inverse Fourier modal transform $\left(\mathrm{FMT}^{-1}\right)$ allows the return from the modal domain to the spatial domain [11].

\section{Antenna Design}

The antenna structure is shown in Figure 1. The antenna patch geometry, shown in Figure 1(a), is inspired on the set of Mandelbrot fractals. The Mandelbrot set, graphically, can be divided into an infinite set of cardioids, with the largest of them located at the center of the complex plane. There is an infinite number of cardioids, which tangentially interconnect the largest cardioid, of many different sizes and whose semimajor axes will tend to zero. Each of these cardioids has its own set of cardioids, whose axes also tend to zero. This process is repeated endlessly, thus generating a Mandelbrot fractal geometry.

In this work, the Mandelbrot set has been used as a basis to develop the microstrip patch antenna structure. The Mandelbrot sequence has been applied in a circle of radius $R=12.5 \mathrm{~mm}$, to generate a quasifractal patch geometry, which can be divided into a set of infinite circles. This patch geometry has been fed by a quarter wavelength microstrip line with characteristic impedance of $50 \Omega$ at the central frequency of the UWB band $(6.85 \mathrm{GHz})$. Figure $1(\mathrm{~b})$ shows the antenna structure considered in this work. The antenna patch is attached on a textile substrate of dimensions $50 \mathrm{~mm} \times 50 \mathrm{~mm}$, with a truncated ground plane to meet the microstrip monopole structure design. Figure 1(c) shows photographs of the front and back views of the fabricated antenna prototype.

The brim santista textile material has been used as microstrip substrate, which has the following structural parameters: thickness $h=1.1 \mathrm{~mm}$, relative permittivity $\varepsilon_{\mathrm{r}}=1.92$, and loss tangent $\tan \delta=0.074$ [13]. The patch and ground plane have been fabricated with pure copper polyester taffeta fabric, woven pure copper which is lightweight and flexible 


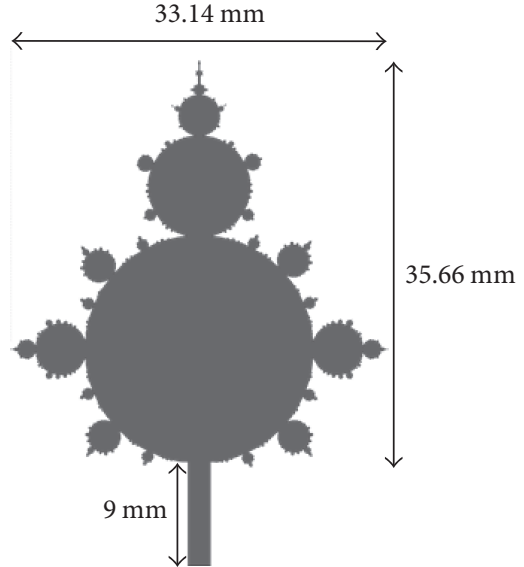

(a)

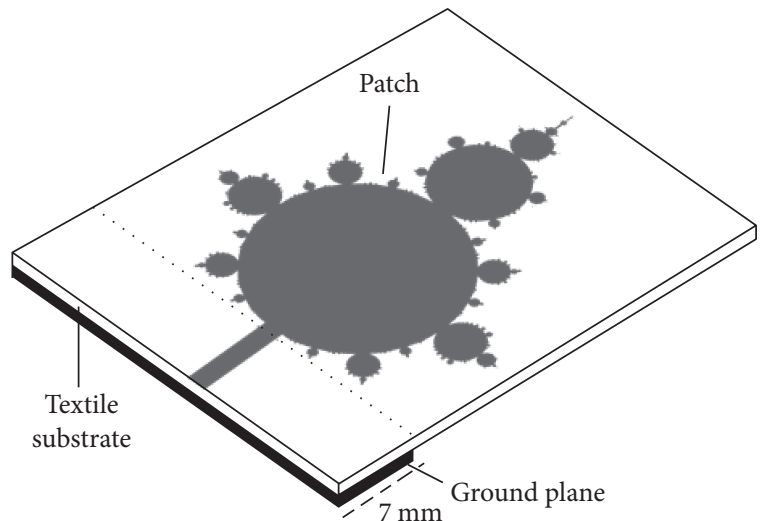

(b)

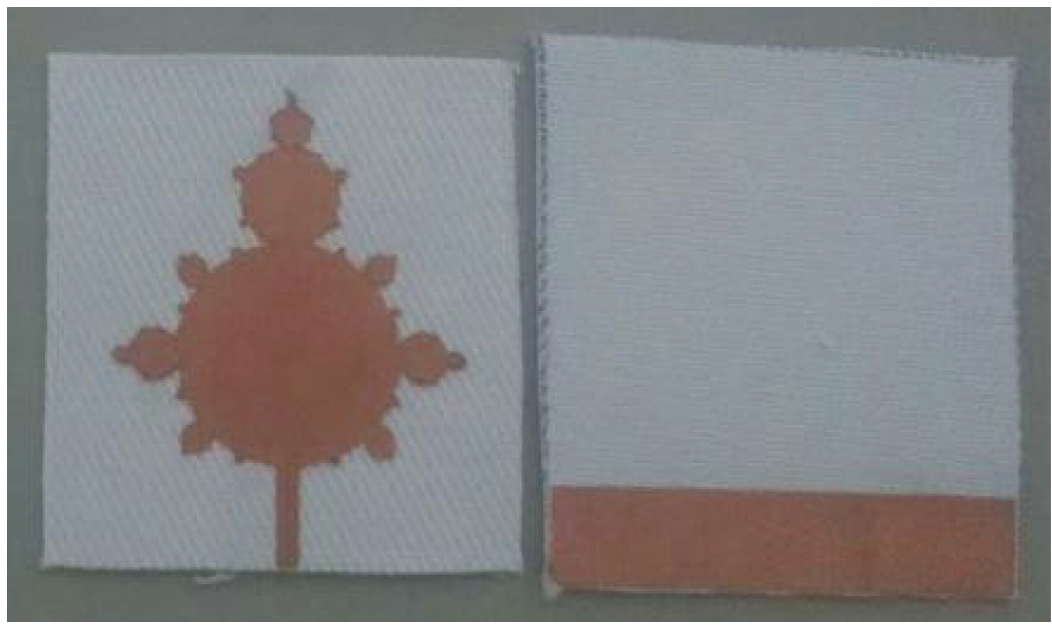

(c)

Figure 1: Mandelbrot monopole patch antenna on textile substrate: (a) antenna patch illustration, (b) antenna structure illustration, and (c) photographs of the fabricated prototype (front and back views).

and with high conductivity, with a thickness of $0.08 \mathrm{~mm}$ and a surface resistance of $0.05 \mathrm{Ohm} / \mathrm{sq}$.

\section{Results and Discussion}

Figure 2 shows calculated results using WCIP method for the monopole microstrip Mandelbrot quasifractal geometry with three different substrates: polyester cotton fabric, brim santista textile, and FR4. These results indicate that, at UWB band, the printed monopole antenna on cotton polyester substrate presents return loss values ranging from $-17.7 \mathrm{~dB}$ (minimum value) to $-8.33 \mathrm{~dB}$ (maximum value). Therefore, for a $-10 \mathrm{~dB}$ bandwidth reference, this antenna does not resonate at the entire UWB band. However, it presents a multiband performance, resonating at important operating frequencies such as $2.5 \mathrm{GHz}, 2.6 \mathrm{GHz}$, and $5.8 \mathrm{GHz}$, used in wireless communication systems. Similarly, the printed monopole antenna on FR4 substrate does not resonate at the entire UWB band. However, unlike the monopole antenna on cotton substrate, it presents a single wideband performance, from $3.93 \mathrm{GHz}$ to $6.93 \mathrm{GHz}$, useful for particular wireless communication systems.

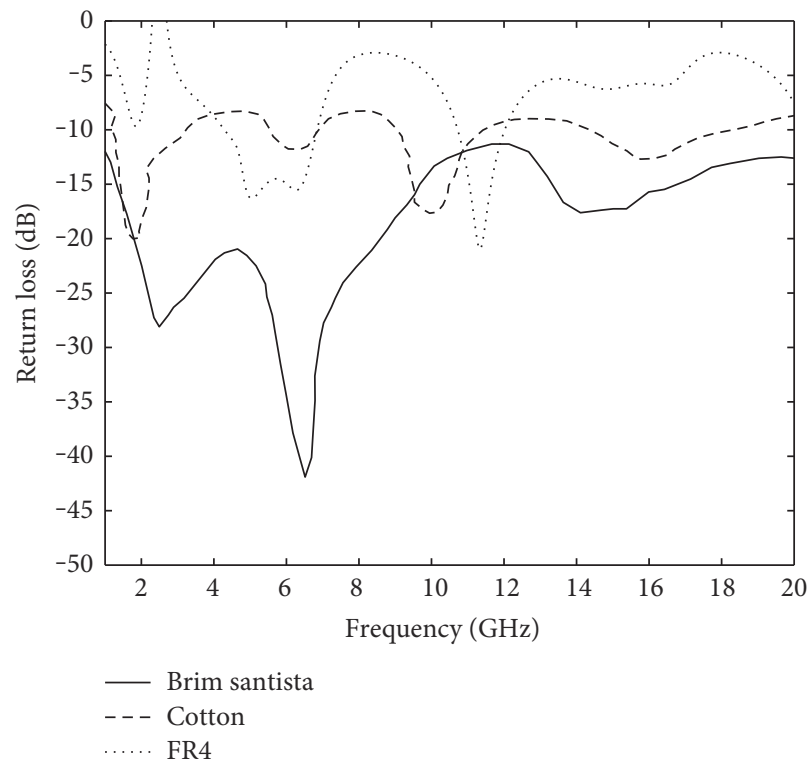

FIGURE 2: WCIP-simulated return loss results for monopole microstrip antennas on different substrates. 


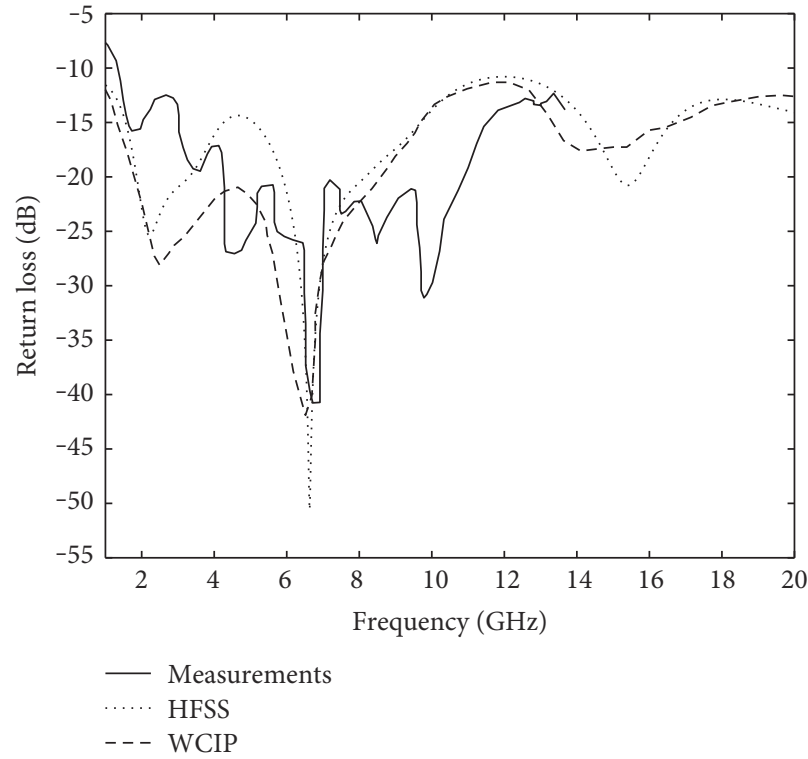

(a)

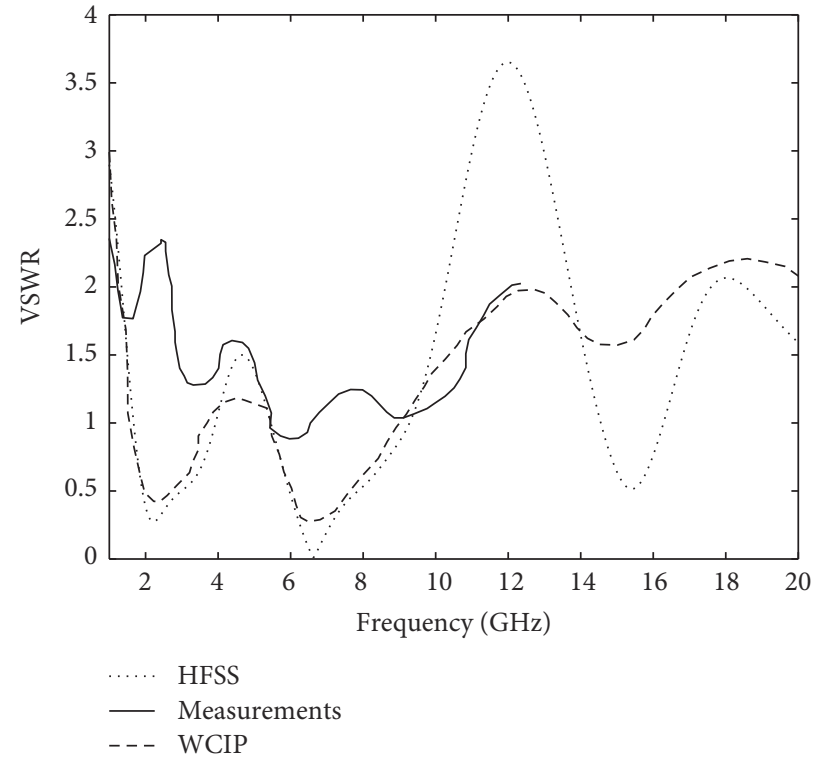

(b)

FIGURE 3: Frequency responses for fractal monopole microstrip patch antenna on brim santista substrate: (a) return loss and (b) VSWR.

In addition, according to the results presented in Figure 2, the printed monopole microstrip antenna on brim santista substrate presents return loss values below the $-10 \mathrm{~dB}$ bandwidth reference within the entire UWB range. Therefore, this antenna can be used in wireless communication systems which operate at the whole UWB range, from $3.1 \mathrm{GHz}$ to $10.6 \mathrm{GHz}$.

To validate the WCIP results presented in Figure 2, HFSS simulation and experimental results have been obtained for the printed monopole patch antenna on brim santista substrate. WCIP, HFSS, and measurements return loss and VSWR results, for the monopole antenna on brim santista substrate, are shown in Figures 3(a) and 3(b), respectively, for comparison purpose. Within the whole UWB band, the antenna has presented (WCIP and HFSS) return loss simulated and measured values below $-10 \mathrm{~dB}$. In addition, a good agreement between simulation and experimental results is verified. Figure 3(b) exhibits simulated and measured results of the antenna VSWR. Observe that the VSWR values are lower than 2 at the entire UWB band, enabling its use in UWB systems.

Considering a maximum value reference of 2 for VSWR and $-10 \mathrm{~dB}$ for return loss, the obtained simulated and measured results are lower than the reference values over the entire frequency band. In addition, a good agreement between simulation and experimental results is verified for the antenna bandwidth.

Figure 4 shows the surface current density distribution on the antenna patch. There is a larger current intensity concentrated in the region of the largest circle structure. The determination of the surface current density is very important when wishing to make changes in the structure to control the patch antenna frequency response.

Figure 5 shows $3 \mathrm{D}$ and $2 \mathrm{D}$ radiation patterns (gain results) for the monopole microstrip patch antenna on brim

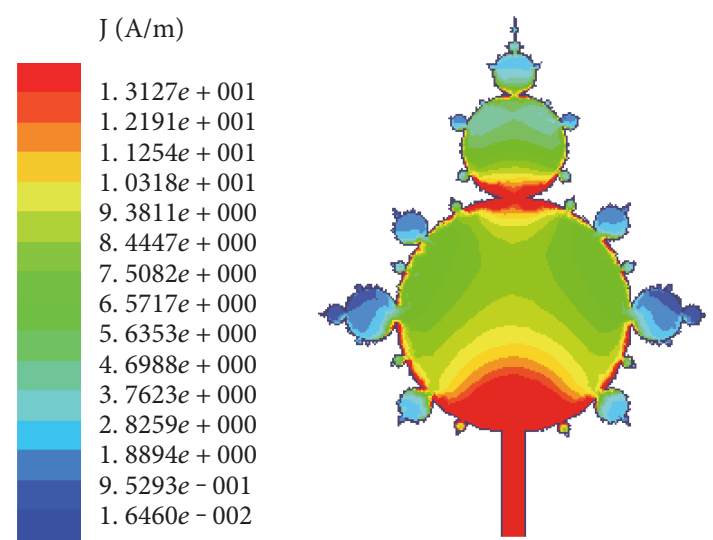

FIgURE 4: Surface current distribution on the fractal patch geometry of the monopole microstrip on brim santista substrate.

santista substrate. In Figure 5(a), a good agreement is observed between WCIP and HFSS software simulation results for $2 \mathrm{D}$ radiation pattern (gain results). It should be emphasized what this work's contribution is in using WCIP to calculate the radiation pattern for the proposed antenna, a fact that has not been reported (as far as we are concerned) in the literature. Considering the $2 \mathrm{D}$ results, the antenna gain keeps almost constant for variations in the range $-100^{\circ}<\theta<100^{\circ}$. In Figure 5(b), the antenna radiation pattern (gain results) looks omnidirectional (HFSS results), a good performance for wireless system applications.

Table 1 presents resonant frequency, VSWR, and gain results for the proposed antenna. These results have been obtained by WCIP formulation, HFSS software, and measurements, for comparison purpose. These results are in good agreement and have been obtained using the lowest value of $s_{11}$, for the resonant frequency $f_{\mathrm{r}}$, and the maximum 


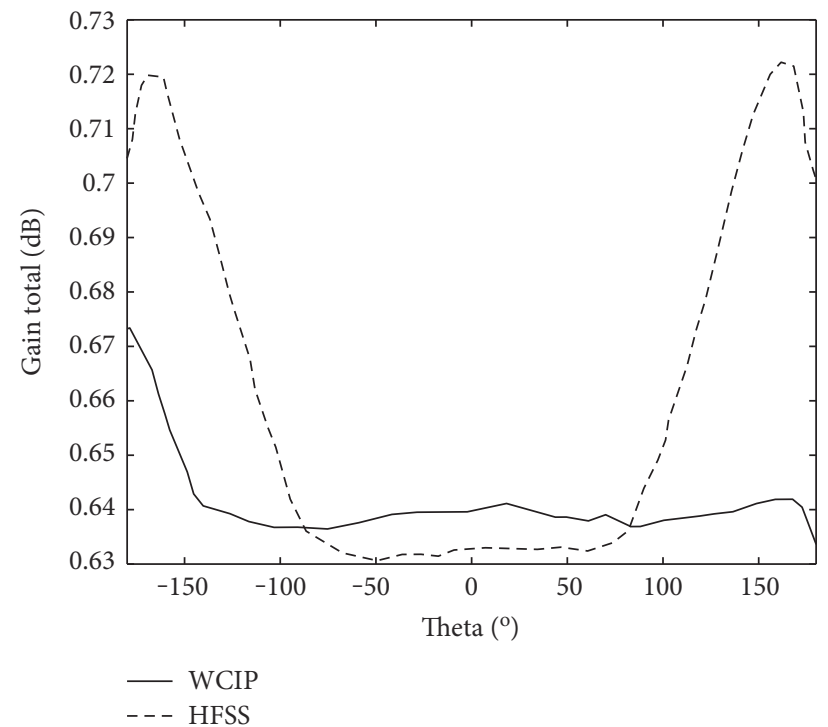

(a)
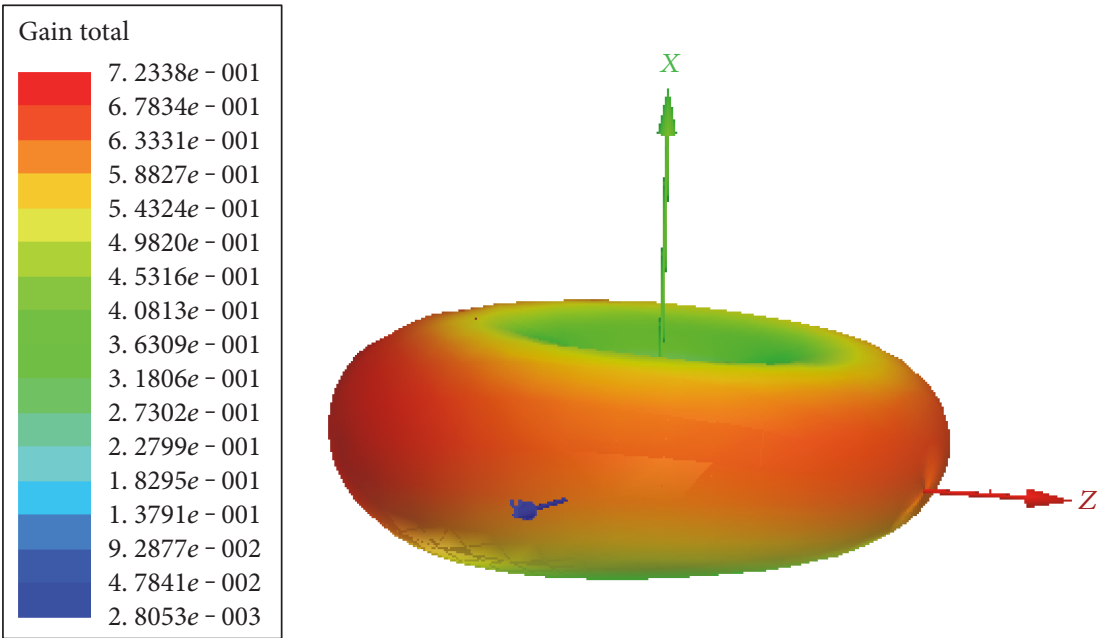

(b)

FIGURE 5: Radiation patterns (gain results) for the monopole microstrip antenna on brim santista substrate: (a) 2D and (b) 3D results.

TABLE 1: Simulation and Measurements Results.

\begin{tabular}{lccc}
\hline Parameter & WCIP & HFSS & Measurements \\
\hline$f_{\mathrm{r}}(\mathrm{GHz})$ & 6.51 & 6.63 & 6.67 \\
VSWR & 1.16 & 1.49 & 1.60 \\
Gain & 0.640 & 0.632 & - \\
\hline
\end{tabular}

VSWR value in the UWB band, and the maximum gain for $-100^{\circ}<\theta<100^{\circ}$.

Based on the results shown in Table 1, the proposed antenna is a good candidate for UWB system applications. In addition, the WCIP formulation has proven to be efficient and successful in characterizing the proposed monopole microstrip patch antennas with a complex Mandelbrot fractal geometry. In addition, it can be used in the analysis of other complex planar structures, such as antennas, filters, couplers, power dividers, and FSSs, in microstrip or CPW geometries, including the analysis of printed circuits on nonconventional materials.

\section{Conclusion}

A microstrip antenna for UWB applications printed on a textile substrate has been analyzed using the WCIP method. The monopole antenna is based on a resonant patch element with Mandelbrot fractal geometry. WCIP formulation has been used in the determination of the antenna resonant frequencies, return loss, and radiation pattern (gain results). The WCIP theoretical, HFSS simulation, and measurement results indicate that the proposed antenna can operate in the whole UWB band. In addition, the monopole antenna has presented omnidirectional radiation characteristics. Finally, an excellent agreement between measured and simulated results has been observed confirming the good performance of the proposed antenna 
and efficiency of the used numerical analysis technique (WCIP method).

\section{Conflicts of Interest}

The authors declare no conflicts of interest regarding the publication of this paper.

\section{Acknowledgments}

This work was partially supported by CNPq, under Covenant 573939/2008-0 (INCT-CSF), CAPES, Federal University of Rio Grande do Norte (UFRN), and Federal Rural University of the Semi-Arid Region (UFERSA).

\section{References}

[1] FCC, FCC First Report and Order on Ultra-Wideband Technology, FCC, Washington, DC, USA, 2002.

[2] G. Reddy, A. Kamma, S. Kharche, J. Mukherjee, and K. S. Mishara, "Cross-configured directional UWB antennas for multidirectional pattern diversity characteristics," IEEE Transactions on Antennas and Propagation, vol. 63, no. 2, pp. 853-858, 2015.

[3] M. A. R. Osman, M. K. A. Rahim, N. A. Samsuri, M. K. Elbasheer, and M. E. Ali, "Textile UWB antenna bending and wet performances," International Journal of Antennas and Propagation, vol. 2012, Article ID 251682, 12 pages, 2012.

[4] E. G. Lim, Z. Wang, J. C. Wang et al., "Wearable textile substrate patch antennas," Engineering Letters, vol. 22, no. 1, pp. 1-8, 2014.

[5] L. Zhang, Z. Wang, and J. L. Volakis, "Textile antennas and sensors for body-worn applications," IEEE Antennas and Wireless Propagation Letters, vol. 11, pp. 1690-1693, 2012.

[6] L. P. Dominique, H. Giddens, M. G. Paterson, S. G. Hilton, and P. J. McGeehan, "Impact of body and clothing on a wearable textile dual band antenna at digital television and wireless communications bands," IEEE Transactions on Antennas and Propagation, vol. 61, no. 4, pp. 2188-2194, 2013.

[7] B. B. Mandelbrot, The Fractal Geometry of Nature, W. H. Freeman and Co., New York, USA, 1982.

[8] K. Falconer, Fractal Geometry - Mathematical Foundations and Applications, John Wiley, Nova Jersey, EUA, 1990.

[9] A. Serres, G. K. F. Serres, G. Fontgalland, R. C. S. Freire, and H. Baudrand, "Analysis of multilayer amplifier structure by an efficient iterative technique," IEEE Transactions on Magnetics, vol. 50, pp. 185-188, 2014.

[10] V. P. Silva Neto, M. J. Duarte, and A. G. D’Assunção, "Full-wave analysis of stable cross fractal frequency selective surfaces using an iterative procedure based on wave concept," International Journal of Antennas and Propagation, vol. 2015, Article ID 401210, 7 pages, 2015.

[11] P. B. C. Medeiros, V. P. Silva Neto, and A. G. D’Assunção, “A compact and stable design of FSS with radial slit circular elements using an iterative method," Microwave and Optical Technology Letters, vol. 57, pp. 729-733, 2015.

[12] M. Titaouine, N. Raveu, A. Gomes Neto, and H. Baudrand, "Electromagnetic modeling of quasi-square open metallic ring frequency selective surface using wave concept iterative procedure," ETRI Journal, vol. 31, no. 1, pp. 77-79, 2009.
[13] G. A. Cavalcante, D. R. Minervino, A. G. D’Assunção Jr., V. P. Silva Neto, and A. G. D'Assunção, "A compact multiband reject inverted double-E microstrip filter on textile substrate," Microwave and Optical Technology Letters, vol. 47, pp. 25432548, 2015.

[14] G. A. Cavalcante, A. G. D'Assunção Jr., and A. G. D'Assunção, "An iterative fullwave method for designing bandstop frequency selective surfaces on textile substrate," Microwave and Optical Technology Letters, vol. 56, pp. 383-388, 2014.

[15] R. Bediraa, A. Gharsallaha, A. Gharbi, and H. Baudrand, "An iterative process based on the concept of waves for electromagnetic scattering problems," Electromagnetics, vol. 22, no. 2, pp. 129-140, 2002.

[16] K. V. Kumar, V. I. Nair, and V. Asokan, "Design of a microstrip fractal patch antenna for UWB applications," in 2015 International Conference on Innovations in Information, Embedded and Communication Systems (ICIIECS), pp. 1-4, Coimbatore, India, March 2015.

[17] M. Naser-Moghadasi, R. A. Sadeghzadeh, T. Sedghi, T. Aribi, and B. S. Virdee, "UWB CPW-fed fractal patch antenna with band-notched function employing folded T-shaped element," IEEE Antennas and Wireless Propagation Letters, vol. 12, pp. 504-507, 2013.

[18] H. Oraizi and S. Hedayati, "Miniaturized UWB monopole microstrip antenna design by the combination of Giusepe peano and Sierpinski carpet fractals," IEEE Antennas and Wireless Propagation Letters, vol. 10, pp. 67-70, 2011. 


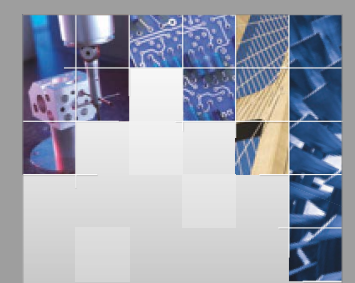

\section{Enfincering}
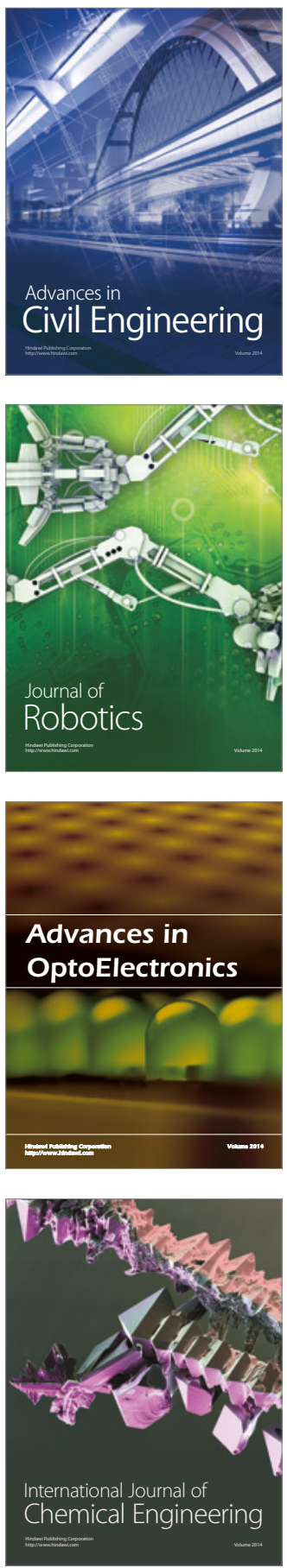

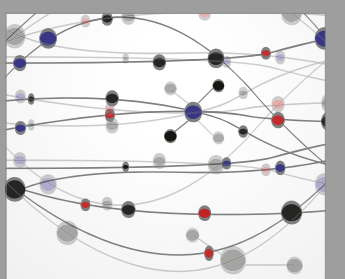

The Scientific World Journal

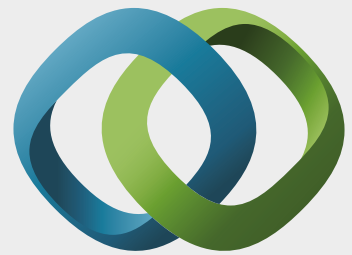

\section{Hindawi}

Submit your manuscripts at

https://www.hindawi.com
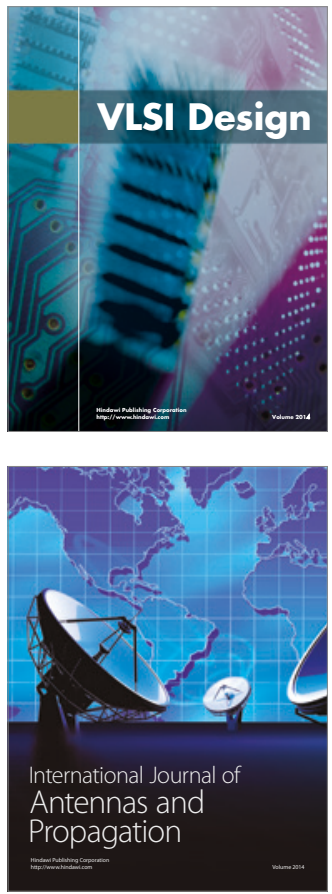

\section{Rotating}

Machinery
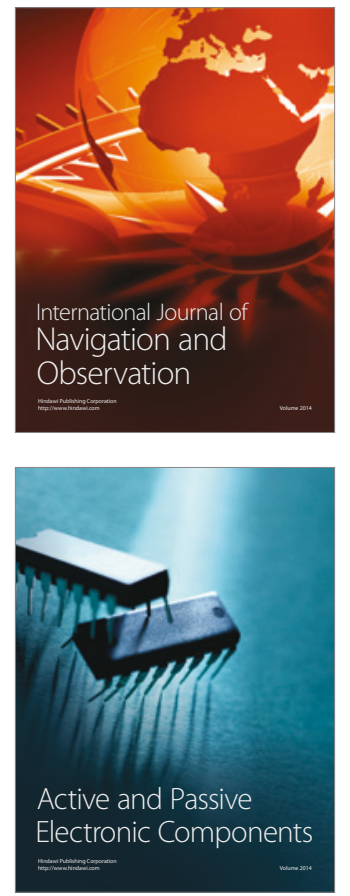
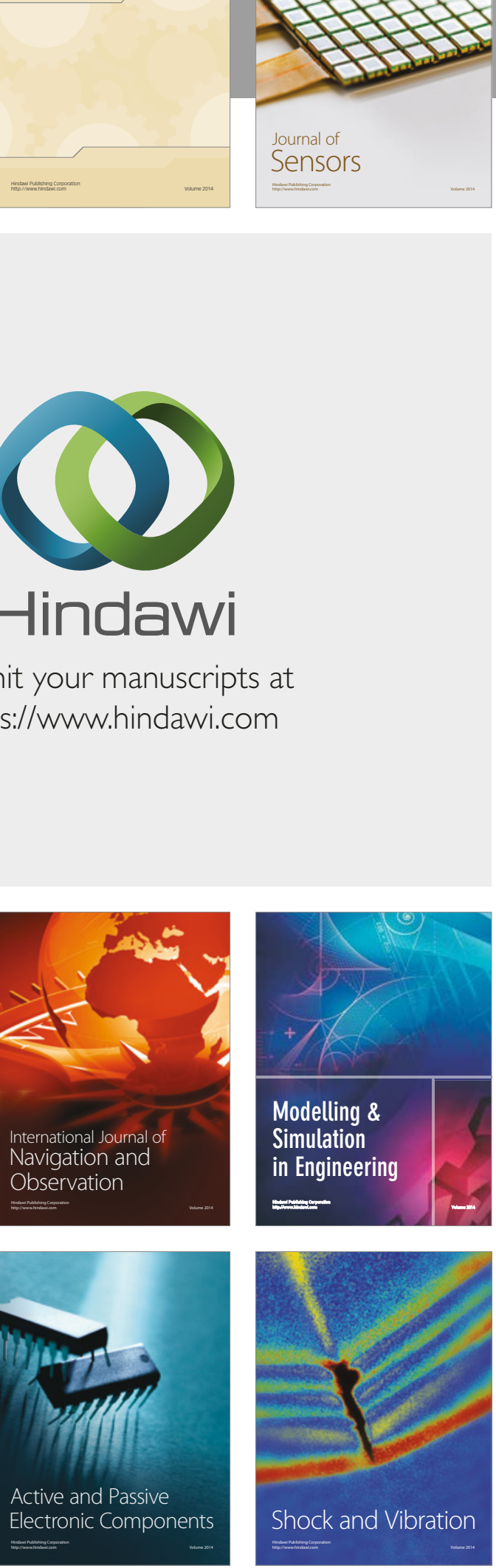
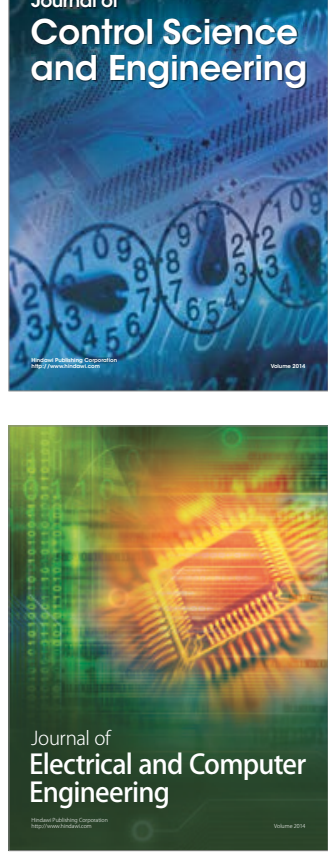

Distributed

Journal of

Control Science

and Engineering
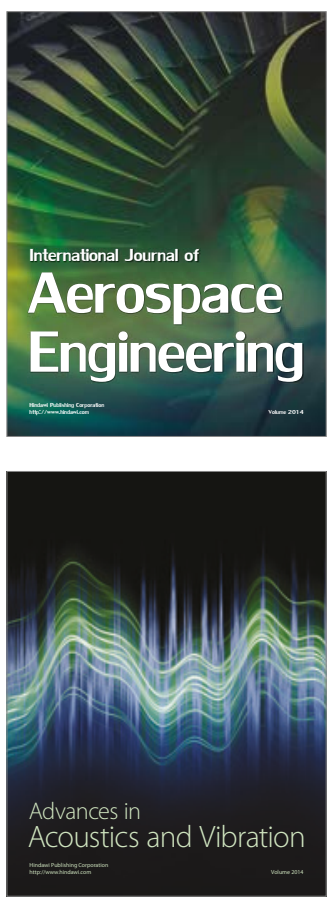

Sensor Networks 